\title{
An Investigation into Relationship among Application of IT on Organizational Performance via Sink's Technique (Case study: Taxation Administrations in North Iranian Provinces)
}

\author{
Meysam Karamipour \\ Young Researchers and Elites Club, Science and Research Branch, Islamic Azad University, Tehran, Iran \\ Email:mkaramipour@srbiau.ac.ir
}

Esmaeel Golij

Department of Accounting "MA", Raja University ,Qazvin, Iran

Soheil Morad Khani

Department of Industrial Management, Karaj Branch, Islamic Azad University, Karaj, Iran

Doi:10.5901/mjss.2016.v7n5s1p9

\begin{abstract}
We examine the relationship among application of Information Technology (IT) in organization and organizational performance based on Sink's technique in Taxation Administrations at Guilan and Mazandaran provinces (north Iranian provinces) in the present article. The methodology of this study is of descriptive and inferential type. Statistical population of the present research includes IT directors, experts, and users in the given organization comprising of 450 participants out of them 50 respondents were chosen by means of simple randomized sampling technique. The standardized questionnaire has been employed a tool for data collection including two inventories relating to IT measurement and organizational performance. The reliability rates of IT related questionnaire and also (organizational performance) questionnaire were acquired 0.915 and 0.855 respectively. Research analysis was carried out at two levels of descriptive and inferential statistics. The research findings showed that there was positive significant relationship among application of the existing IT level in organization and organizational performance and application of IT had positive significant relationship with variables of efficiency, quality, effectiveness, quality of working life, creativity, innovation, and productivity, but it has positive relationship with variable of profitability that was not statistically significant. The maximum and minimum rates of relationship belonged to IT application with creativity and innovation as well as IT application with profitability at levels of 0.406 and 0.206 , respectively. Overall, results of this study indicate that improvement in organizational performance based on Sink's technique is highly affected by application of IT.
\end{abstract}

Keywords: Information Technology (IT), Organizational performance, Effectiveness, Sink's technique.

\section{INTRODUCTION}

Today community is an organizational community and organizations form the main cornerstone in current community. Alternately, developments and changes have occurred very quickly within the field of activity of organizations during recent decades to the extent that administration of affairs in organizations has been turned into complicated activity. These changes, which take place in various fields of environmental factors, social, political, technological, and cultural conditions in community, may lead to change in goals, activities, and tasks of organizations. Thus, organizations have to adapt the goals, activities, and tasks of organizations in such a dynamic environment. Organizations continually try to improve their performance and employ all of available tools and facilities in this regard. IT is one of the foremost tools for development and enhancement and improvement of performance and increase the potential in organizations. Today, advancement in the fields of digital IT, Information and Communication Technology (ICT), and the relevant innovations leads to enormous developments in technique of data collection, storage, processing, transfer, and display. Electronic networks are setup mainly with the motive and goal of rising efficiency in various organizations. In fact, directors have found that many activities and businesses may be more easily and readily done via email and various types of software. But, when we go to the higher level than this level, we will witness emerging of behavioral and organizational changes. IT causes the way of spending time by personnel, domain of relations and contacts between personnel, and level of 
knowledge of any individual about anything to be extremely changed. Therefore, in addition to its impact on efficiency of behavioral and intellectual patterns, IT may also transform organizational lifestyle. IT has been generally called as an umbrella due to its wide range in basic equipments, programs, services, and technology. In fact, IT is an umbrella that covers mechanical- user integrated systems that provide the needed information to support from operational, administrative, analytical and decision-making tasks in an organization [1]. Despite of the fact that the used models in IT evaluation and measurement have not been automatically designated for IT, they have been often employed in this field. Of these paramount criteria one can refer to financial, strategic, competitiveness, effectiveness, quality improvement, and requirements criteria namely method of meeting external needs, satisfaction of users, external consent, and risks with events [2]. Nonetheless, nature of IT is assumed as an infrastructure that hinders its accurate measurement [3]. Measurement techniques have been often employed statistically and for measurement of IT performance based on IT influence on performance. IT for an organization has not been exclusively measured in all aforesaid studies. The directors should be informed accurately about IT level in organization before making any decision and or planning for investment and change in their structure.

\section{Definition of Problem}

A trend that has started in application of informatics technologies in organizations advances toward ever-increasing development. This trend has progressed during forthcoming years in such a way that covers all units and internal elements of organizations [4]. During recent years, many enormous investments have been implemented to equip organizations with IT facilities including computer hardware, professional and administrative computer programs, and developing of internal networks. This issue has increased inputs into the organizations and it is expected to lead to increase in outputs and productivity and consequently improvement in performance at organizations as well [5] since execution of plans and techniques of achieving of their goals are manifested in any organization within framework of performances of the given organization [6]. The rising wave of using IT has covered our country during recent years and many organizations highly tended to utilize and exploit from IT and given this fact that no factor will affect on performance of organizations in future more than the revolution we witness its occurrence in IT so conducting study in this field will be a vital task [7]. As a result, the present research deals with study on relationship among IT and organizational performance and the basic question which may be raised following to its acquisition is that if there is any significant relationship among application of IT at existing level in organization and performance of the studied organization. One can also refer to subject of ICT user in commerce and economy and e-commerce in our country. In the current research, we have searched for finding that how the relationship is among IT application with organizational performance throughout Guilan and Mazandaran Province Taxation Organizations. Whereas this organization is a governmental executive organization and giving services to regional people is one the given main objectives thus depending on type of this organization which differs from production and non-profit enterprises, Sink' technique has been adapted to evaluate its performance.

\subsection{Sink's technique}

Sink's seven-factor technique is one of models for evaluation of (organizational) performance. D. Scott Sink introduced seven-factor system (Efficiency, effectiveness, quality, profitability, productivity, quality of working life, creativity and innovation) to evaluate organizational performance. This comprehensive model covers all performance aspects and it is assumed as a good point for developing measurement systemic approach [11]. An image of performance seven-criterion relations is given in the following.

Fig 1: Sink's model

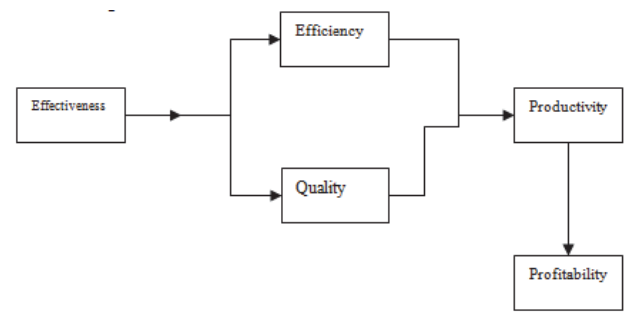




\section{Research Questions}

Major question: From viewpoint of directors and experts of Guilan and Mazandaran Taxation Administrations, is there any significant relationship among application of IT at existing level in organization with organizational performance?

Question I: From viewpoint of directors and experts of Guilan and Mazandaran Taxation Administrations, is there any significant relationship among application of IT at existing level in organization with organizational effectiveness?

Question II: From viewpoint of directors and experts of Guilan and Mazandaran Taxation Administrations, is there any significant relationship among application of IT at existing level in organization with organizational efficiency?

Question III: From viewpoint of directors and experts of Guilan and Mazandaran Taxation Administrations, is there any significant relationship among application of IT at existing level in organization with organizational quality?

Question IV: From viewpoint of directors and experts of Guilan and Mazandaran Taxation Administrations, is there any significant relationship among application of IT at existing level in organization with organizational productivity?

Question V: From viewpoint of directors and experts of Guilan and Mazandaran Taxation Administrations, is there any significant relationship among application of IT at existing level in organization with Quality of working life in organization?

Question VI: From viewpoint of directors and experts of Guilan and Mazandaran Taxation Administrations, is there any significant relationship among application of IT at existing level in organization with organizational creativity and innovation?

Question VII: From viewpoint of directors and experts of Guilan and Mazandaran Taxation Administrations, is there any significant relationship among application of IT at existing level in organization with organizational profitability?

\subsection{Research hypotheses:}

The research major hypothesis is that from perspective of directors and experts of Guilan and Mazandaran Taxation Administrations, there is significant relationship among application of IT at exiting level in organization with organizational performance and based on above-said criteria of organizational performance, the research minor hypotheses are as follows:

First hypothesis: According to attitude of directors and experts of Guilan and Mazandaran Taxation Administrations, there is significant relationship among application of IT at exiting level in organization with organizational effectiveness.

Second hypothesis: According to attitude of directors and experts of Guilan and Mazandaran Taxation Administrations, there is significant relationship among application of IT at exiting level in organization with organizational efficiency.

Third hypothesis: According to attitude of directors and experts of Guilan and Mazandaran Taxation Administrations, there is significant relationship among application of IT at exiting level in organization with quality.

Fourth hypothesis: According to attitude of directors and experts of Guilan and Mazandaran Taxation Administrations, there is significant relationship among application of IT at exiting level in organization with organizational productivity.

Fifth hypothesis: According to attitude of directors and experts of Guilan and Mazandaran Taxation Administrations, there is significant relationship among application of IT at exiting level in organization with organizational working life.

Sixth hypothesis: According to attitude of directors and experts of Guilan and Mazandaran Taxation Administrations, there is significant relationship among application of IT at exiting level in organization with organizational creativity and innovation.

Seventh hypothesis: According to attitude of directors and experts of Guilan and Mazandaran Taxation Administrations, there is significant relationship among application of IT at exiting level in organization with organizational profitability.

\subsection{Goals of research implementation}

As it inferred from title of this study, the general objective of the current research is to analyze relationship among application of IT at existing level in organization with organizational performance. The research minor goals are also as follows:

1. Study on relationship among application of IT at the existing level in organization with organizational 
effectiveness .

2. Analysis of on relationship among application of IT at the existing level in organization with organizational efficiency.

3. Study on relationship among application of IT at the existing level in organization with organizational quality .

4. Survey on relationship among application of IT at the existing level in organization with organizational productivity.

5. Analysis of relationship among application of IT at the existing level in organization with quality of working life

6. Study on relationship among application of IT at the existing level in organization with organizational efficiency creativity and innovation

7. Analysis on relationship among application of IT at the existing level in organization with organizational profitability

\subsection{Research variables}

\subsubsection{Dependent variable:}

It is a variable in which its variance is affected by independent variable [2]. Organizational performance is dependent variable in this study.

\subsubsection{Independent variable:}

It is a variable that positively or negatively affects on dependent variable and to the extent any increase occurs in independent variable, the same increase or decrease will take place in dependent variable as well. IT is independent variable in hypothesis of the present research.

\subsubsection{Statistical population:}

The related statistical population for analysis on relationship among IT and organizational performance includes directors, experts, and personnel in the studied organizations namely Guilan and Mazandaran Taxation Administrations have been actively involved and they have experienced IT within field of their own activity that forms statistical population in the present investigation where their quantity was about 450 participants (in first group: Guilan Province) and 350 participants at second group (Mazandaran Province). The following formula has been used to calculate sample size because the size of population is limited in the current study [5].

(1)

$$
n=\frac{N Z_{a / 2}^{2} \sigma_{x}^{2}}{\varepsilon^{2}(N-1)+Z_{a / 2}^{2} \sigma_{x}^{2}}
$$

Where:

$N=$ Sample size

$n=$ Sample size

$a=$ Statistical confidence level (95\%)

$\varepsilon=$ measurement error

$\sigma=$ Standard deviation of population

We know that sample size is $N=450$ in first population. Given that measurement error is set as 0.07 and with respect to similar experience standard deviation of community is supposed as $25 \%$ [4], we will have:

(2)

$$
n=\frac{450(1 / 96)^{2}(0 / 25)^{2}}{(0 / 07)^{2}(450-1)+(1 / 96)^{2}(0 / 25)^{2}}=\frac{108 / 1}{2 / 44}=44 / 28
$$

The minimum quantity of sample size should not be less than 45 participants so that sample size has been selected as 50 in the present study and in order to choose 50 respondents out of total 450 participants, simple randomized sampling technique has been utilized.

For this sample, parameters of central tendency and dispersion relating to ICT are given in the following table: 
Table 1: Parameters of central tendency and dispersion relating to ICT

\begin{tabular}{|l|c|c|c|c|c|c|}
\hline Parameters & Question 1 & Question 2 & Question 3 & Question 4 & Question 5 & Question 6 \\
\hline Mean & 2.825 & 3.56 & 4.5 & 3.275 & 3.120 & 2.225 \\
\hline Median & 3 & 4 & 5 & 3 & 3 & 2 \\
\hline Mode & 3 & 4 & 5 & 3 & 5 & 1 \\
\hline Standard deviation & 1.23802 & 1.07537 & 0.84732 & 1.2606 & 1.53902 & 1.25038 \\
\hline Minimum & 1 & 1 & 2 & 1 & 1 & 1 \\
\hline Maximum & 5 & 5 & 5 & 5 & 5 & 5 \\
\hline Total value & 113 & 146 & 180 & 131 & 125 & 89 \\
\hline Quantity & 55 & 55 & 55 & 55 & 55 & 55 \\
\hline
\end{tabular}

The maximum mean score belongs to Question-3 (using telephone) with value 4.5 while the minimum mean score is related to Question-6 (using corporate website) with value 2.225. These results are given for other tables:

IT- decision-making supporting system: The maximum mean value belongs to data display software as schematic and the minimum mean value is related to decision-making supporting systems.

Official IT: The highest related mean value belongs to text-processor while lowest mean score is related to performance analysis systems.

\section{Inferential Statistics}

In this section, the relations among research variables will be calculated and examined using bivariate statistical techniques. The following table represents relationship among application of ICT, IT support, official and financial IT as well as performance parameters.

Table 2: The relationship among application of ICT, IT support, official and financial IT and performance parameters

\begin{tabular}{|c|c|c|c|c|c|c|c|c|}
\hline \multicolumn{2}{|l|}{ Criterion } & Efficiency & Quality & Quality of working life & Innovation & \begin{tabular}{|l} 
Profitability \\
\end{tabular} & Effectiveness & Productivity \\
\hline \multirow{2}{*}{ IT in communication (ICT) } & $r$ & 0.231 & 0.378 ** & 0.411 ** & 0.474 ** & 0.180 & 0.292 & 0.333 * \\
\hline & $p$ & 0.152 & 0.016 & 0.008 & 0.002 & 0.266 & 0.067 & 0.036 \\
\hline \multirow{2}{*}{ It decision-making support } & $r$ & $0.51^{* *}$ & 0.361 ** & 0.231 & 0.200 & 0.221 & 0.144 & 0.319 \\
\hline & $p$ & 0.001 & 0.022 & 0.152 & 0.217 & 0.170 & 0.377 & 0.045 \\
\hline \multirow{3}{*}{ Official- financial IT } & $r$ & $0.535^{\text {** }}$ & $0.334^{* *}$ & 0.179 & 0.217 & $0.408^{* \star}$ & 0.172 & 0.319 * \\
\hline & $p$ & 0.001 & 0.036 & 0.268 & 0.178 & 0.009 & 0.291 & 0.045 \\
\hline & $\mathrm{N}$ & 55 & 55 & 55 & 55 & 55 & 55 & 55 \\
\hline
\end{tabular}

As it observed, there is strong positive relationship among application of ICT with quality and innovation and these relations are significant at confidence level 99\%. Similarly, there is direct relationship among application of ICT with efficiency and effectiveness but this relation is not significant and based on test results, there is significant correlation between two variables of ICT and productivity with intensity of 0.33 at confidence level $95 \%$. Likewise, this issue may be analyzed for IT decision-making support and official and financial IT. Finally, we achieved the following findings by analysis on official IT, ICT, It decision-making support, and organizational performance. ICT is positively and significantly related to organizational performance. There is positive relationship among IT decision-making support and official IT with organizational performance but this relation is not statistically significant.

Table 3: The relationship among IT and organizational performance

\begin{tabular}{|l|c|c|c|c|}
\hline Criterion & & ICT & IT decision-making support & Official- financial IT \\
\hline \multirow{3}{*}{ Official- financial IT } & $\mathrm{r}$ & $0.420 * *$ & 0.295 & 0.275 \\
\cline { 2 - 5 } & $\mathrm{p}$ & 0.009 & 0.090 & 0.095 \\
\cline { 2 - 5 } & $\mathrm{N}$ & 55 & 55 & 55 \\
\hline${ }^{* *}$ Correlation is significant at level 0.01 (two domains) & ${ }^{*}$ Correlation is significant at level 0.05 (two-domains) \\
\hline
\end{tabular}




\subsection{Testing of research hypotheses:}

In this part, the above-mentioned hypotheses are tested and decisions are made for statistical and practical purposes. These findings have been derived using Spearman's correlation coefficient and by the aid of SPSS software. Null hypothesis and refuted hypothesis are formulated as follows where null hypothesis denotes that there is no significant correlation among application of IT and variables (efficiency and quality etc). For example, according to following table, there is relationship among IT application with efficiency with intensity of 0.48 at confidence level $99 \%$. Therefore, null hypothesis is rejected and the opposite hypothesis is approved. Thus, there is significant relationship among these two variables that may not be due to chance or randomly. This relationship expresses that as IT application increases; probably the efficiency is improved in organizational activities.

$$
\begin{aligned}
& \text { Ho: } \rho=0 \\
& \text { H A: } \rho \neq 0
\end{aligned}
$$

\begin{tabular}{|c|c|c|c|c|c|c|c|c|}
\hline \multicolumn{2}{|l|}{ Criterion } & Efficiency & Quality & Quality of working life & Innovation & Profitability & Effectiveness & Productivity \\
\hline \multirow{3}{*}{ Total IT (ITU) } & $r$ & $0.48 * *$ & $0.368 \mathrm{v}$ & 0.324 * & 0.371 * & 0.299 & 0.191 & 0.340 * \\
\hline & $p$ & 0.002 & 0.019 & 0.042 & 0.018 & 0.016 & 0.238 & 0.032 \\
\hline & $\mathrm{N}$ & 55 & 55 & 55 & 55 & 55 & 55 & 55 \\
\hline
\end{tabular}

Table 4: Application of IT efficiency

\subsubsection{First hypothesis:}

'There is significant relationship among IT application and efficiency.'

So, null hypothesis and its opposite hypothesis are formulated as follows:

$H_{0}: \rho=0$

$H_{A}: \rho \neq 0$ efficiency.

The null hypothesis implies that there is no correlation or significant correlation among IT application with

Using Spearman's ranking test in which the calculations were done by SPSS software, it was disclosed that there is relationship with intensity of 0.48 among IT application with efficiency at confidence level $99 \%$ (bidirectional test). Therefore, null hypothesis is rejected and opposite hypothesis is accepted. Thus, there is significant relationship between these two variables that may not be by chance or randomly. This relationship expresses that with increase in IT application; probably the rate efficiency is improved in organizational activities.

\subsubsection{Second hypothesis:}

'There is significant relationship among application of IT with quality.'

So, null hypothesis and its opposite hypothesis are formulated as follows:

$$
\begin{aligned}
& H_{0}: \rho=0 \\
& H_{A}: \rho \neq 0
\end{aligned}
$$

The null hypothesis implies that there is neither correlation nor significant correlation among IT application and quality.

As it seen in Table (4), there is significant relationship among application of IT and quality with intensity of 0.368 at significance level 95\% (bidirectional test). Therefore, null hypothesis is rejected and the opposite hypothesis is verified. Thus, there is significant relationship among both variables and it may not be by chance or randomly. This relationship denotes that as rate of IT application increases; probably it is added to quality of organizational activities.

\subsubsection{Third hypothesis:}

'There is significant relationship among IT application with creativity and innovation.'

So, null hypothesis and opposite hypothesis are formulated as follows: 


$$
\begin{aligned}
& H_{0}: \rho=0 \\
& H_{A}: \rho \neq 0
\end{aligned}
$$

The null hypothesis implies that there is no correlation or significant correlation among IT application with creativity and innovation.

With respect to the following table, there is relationship among application of IT with creativity and innovation and this relationship is significant with intensity of 0.32 at confidence level $95 \%$. Therefore null hypothesis is rejected and opposite hypothesis is confirmed. This relationship implies that with increase in IT application; probably it is added to creativity and innovation in organizational climate.

\subsubsection{Fourth hypothesis:}

'There is significant relationship among IT application with quality of working life.'

So, the null hypothesis and its opposite hypothesis are formulated as follows:

$$
\begin{aligned}
& H_{0}: \rho=0 \\
& H_{A}: \rho \neq 0
\end{aligned}
$$

The null hypothesis implies that there is no correlation or significant correlation among IT application with quality of working life. The resultant findings from this study denote the existing positive relationship among IT application with quality of working life and this relationship is statistically significant with intensity of 0.324 at confidence level $95 \%$ and this implies that with increase in application of IT; probably quality of working life is improved for personnel. Therefore null hypothesis is rejected and the opposite hypothesis is accepted. This relationship represents this point that as IT application increases; probably it is added to quality of working life.

\subsubsection{Fifth hypothesis:}

'There is significant relationship among application of IT with profitability.'

So, null hypothesis and opposite hypothesis may be formulated as follows:

$$
\begin{aligned}
& H_{0}: \rho=0 \\
& H_{A}: \rho \neq 0
\end{aligned}
$$
profitability.

The null hypothesis denotes that there is no correlation or significant correlation among IT application and

As it seen in Table (4), there is direct relationship among IT application with profitability but this relationship is not statistically significant. Thus, null hypothesis may not be rejected in this regard.

\subsubsection{Sixth hypothesis:}

'There is significant relationship among IT application and effectiveness.'

Thus, null hypothesis and opposite hypothesis may be formulated as follows:

$$
\begin{aligned}
& H_{0}: \rho=0 \\
& H_{A}: \rho \neq 0
\end{aligned}
$$

The null hypothesis implies that there is neither correlation nor significant correlation among IT application with effectiveness. The statistical results show that there is very weak relationship among IT application and effectiveness and despite of its positive nature it is not statistically significant. This point denotes that although application of IT may facilitate doing some activities that influence typically in variable of effectiveness, this relationship may be indirect and rising organizational effectiveness may not be attributed to improvement in IT application. Therefore, null hypothesis may not be rejected in the existing assumption.

\subsubsection{Seventh hypothesis:}

'There is significant relationship among IT application with productivity.'

Thus, null hypothesis and its opposite hypothesis are formulated as follows: 
$H_{0}: \rho=0$
$H_{A}: \rho \neq 0$

The null hypothesis implies that there is no correlation or significant correlation among IT application with productivity. The research findings indicate the existing positive significant relationship among IT application with productivity. This relationship is significant at confidence level 95\% in which with increase in application of IT; probably the rate of productivity is improved. Therefore, null hypothesis is rejected and the opposite hypothesis is approved. It can be concluded that rising of IT application may probably lead to increase in productivity at organization.

Finally, we examine research major hypothesis i.e. 'there is significant relationship among IT application and organizational performance'.

Thus, null hypothesis and its opposite hypothesis are formulated as follows:

$$
\begin{aligned}
& H_{0}: \rho=0 \\
& H_{A}: \rho \neq 0
\end{aligned}
$$

The null hypothesis implies that there is neither correlation nor significant correlation among IT application with organizational performance.

Based on Table (6), it is observed that there is positive significant relationship among application of IT with organizational; performance with intensity of 0.349 at confidence level $95 \%$. Thus, null hypothesis is rejected and opposite hypothesis is verified. Therefore it can be concluded that with increase in IT application; probably organizational performance is improved.

Table 5: IT application versus organizational performance

\begin{tabular}{|l|c|c|}
\hline Criterion & & ITU \\
\hline \multirow{3}{*}{ Organizational performance } & $\mathrm{r}$ & $0.349 *$ \\
\cline { 2 - 3 } & $\mathrm{p}$ & 0.027 \\
\cline { 2 - 3 } & $\mathrm{N}$ & 55 \\
\hline${ }^{* *}$ Correlation is significant at level 0.01 (two domains) \\
${ }^{*}$ Correlation is significant at level 0.05 (two-domains) \\
\hline
\end{tabular}

\section{Conclusion}

With respect to statistical results, IT different forms have certainly affected on performance aspects and this, in turn, will be effective on improving organizational total performance. Of course, this issue is influenced by some other factors as well out of which one can refer to these foremost factors that affect on productivity of these technologies including organizational infrastructures and the efficient environmental factors. Whereas this organization is a governmental and executive organization thus it is extremely under the influence of environmental factors (rules and regulations) where rate of their impact may be the same as of important organizational factors and they can affect on efficiency and effectiveness of organizational activities and this point that measurement of these factors is a difficult or impossible task.

\section{Some Suggestions for Future Studies}

1. It is suggested to researchers, particularly students, within a regular and systematic plan to select each of the studied criteria in a research and to examine deeply and carefully those criteria in an organization. Typically, the given result of this technique of study will have high potential for the studied organization.

2. It is suggested to evaluate organizational performance by other related techniques such Balanced Scorecard.

3. It is suggested to conduct comparative study on this issue among several executive-servicing organizations.

4. It is recommended to use effect of IT on performance in field studies rather than using correlation coefficient and regression certainly by means difference technique. If both methods were followed by negative or positive results the given results would be more reliable as long as only one technique is employed.

\section{References}

[1] Azadikhah, Majid, (2007), Evaluation and order preference of IT efficient factors in supply chain using MADM technique (SAIPA YADAK Automotive Group), MA thesis, Guilan University, Department of Literature and Human Sciences 
[2] Al-Hosseini, Seyed Hassan, (2000), Organizational permanent engineering theory (C.E.O) (Interpretation of permanent change in institution at organizations as thriving field for individual and community), Hormozgan Province Pub, $1^{\text {st }}$ Ed, Banda Abbas

[3] Alvani, Seyed Mehdi \& Riahi, Behrooz, (2003), measurement of quality of services in public sector, Iranian Center for Education and Industrial Studies Publication

[4] Alvani, Seyed Mehdi \& Naghavi, Mir Ali, (2003), Balanced Scorecard Model: A model for measurement of performance in public sector, Quarterly of Management Studies, vols. 37\&38, p 6

[5] Umea, Sekaran, (2001), Methodology in management, transl. Sayebi, Mahmud, Tehran: Public administration and education center

[6] Attaran, M., (2003) "Information Technology and Business process re-design", Business process Management Journal, Vol.9 No 4, p 44.

[7] Attewell, P. (2004): "Why Productivity Remains a Key Measure of IT Impact", paper presented to the Productivity Impact of Information Technology Investments Conference, Charleston pp. 2-15.

[8] Baily, M., R. Gordon (2006): " The Productivity Slowdown, Measurement Issues, and the Explosion of Computer", Power In: Brookings Papers on Economic Activity, Vol.1, pp. 347-420.

[9] Beaumaster Suzanne, (1999), "Information Technology Implementation Issues: An Analysis", Virginia, Blacksburg, ph.D. Thesis, pp24-35.

[10] Brynjolfsson, E. Hitt, L.M., (2000) "Beyond Computation: Information Technology , Organizational Transformation and Business performance", Journal of Economic Perspectives, 14 (4), pp. 23-48.

[11] Brynjolfsson, E. Yang, S., (1996) Information Technology and Productivity: A review of the Literature, Advanced in Computers, Academic Press 43, pp.179-214.

[12] respi, G., Criscuolo, C., and Haskel, J. (2006); " Information Technology , Organizational Change and productivity Growth: Evidence from UK Firms “, Working paper, No.558, Department of Economics, Queen Mary University of London.

[13] Dedrick J., Vijay T, Rouheth L. (2003); "Information Technology and Economic Performance: Critical Review of the Empirical Evidence", ACM Survays, 35(1), March, pp.1-28.

[14] Dehning E., and E. D Kevin, S. Theophanis. (2004); "Information Technology and Organizational Slack", International Journal of Accounting Information systems, pp. 51-63. 